\title{
COSTA RICA: LA SITUACIÓN DE LAS PERSONAS CON DISCAPACIDAD EN PERSPECTIVA HISTÓRICA Y ACTUAL
}

\author{
Mariana Campos Vargas \\ mariana.campos@ucr.ac.cr \\ Universidad de Costa Rica
}

\section{RESUMEN}

Esta investigación es un análisis de la situación de las personas con discapacidad en Costa Rica, tanto en el pasado como en el presente, a partir de los datos disponibles desde 1821 hasta el día de hoy. El estudio presenta la institucionalidad que se ha creado para la atención de ese sector de nuestra población. Las fuentes que se emplearán para ese propósito serán las siguientes: datos censales, normativa pasada y vigente e información sobre las instituciones y organismos relacionados con esa población. El principal hallazgo se refiere a la importancia de la trayectoria institucional previa en materia de discapacidad en el país, que hoy permite sostener los logros alcanzados, a pesar de la época de ajustes.

Palabras clave: Costa Rica, discapacidad, datos censales, normativas, organismos.

\section{COSTA RICA: THE SITUATION OF PEOPLE WITH DISABILITIES \\ IN HISTORICAL AND CURRENT PERSPECTIVE}

\section{Abstract}

This research is an analysis of the situation of people with disabilities in Costa Rica, in the past and present, based on the data available from 1821 to this day, referring to the institutional framework that has been created for the attention of this particular sector of the population. The sources that will be used for this purpose are going to be census data, past and current regulations and available information of the institutions and organism present about institutional structures and agencies concerning the situation of people with disabilities. The main discovery refers to the importance of the previous institutional path in the field of disability within the country, which today allows it to sustain the achievements, despite the adjustments period in the country.

KeYwords: Costa Rica, disability, census data, regulations, agencies. 


\section{INTRODUCCIÓN}

En este trabajo se aborda el estudio de factores del contexto nacional, así como de los actores de la sociedad civil y del Estado, que influyeron y determinaron la creación de instituciones para la atención de población con discapacidad en Costa Rica. De igual forma, se mencionan elementos del contexto internacional que favorecieron el surgimiento de esa institucionalidad, para ofrecer una perspectiva, tanto en el pasado como en el presente, acerca de la situación de ese segmento poblacional en el país.

En Costa Rica, las políticas sociales del Estado ${ }^{1}$ han tenido como componentes acciones de diversa naturaleza: complementaria (alimento, techo, cuidado), supletoria (sustitución permanente), rehabilitación social (capacitaria) y preventiva (evitar comportamiento específico), con el objetivo de eliminar circunstancias desventajosas y preservar instituciones básicas. Esas acciones y objetivos se han centrado en algunos de los segmentos más vulnerables de la población. Ese es el caso de los niños, las mujeres, los ancianos, grupos urbanos y rurales marginales y personas en condición de discapacidad.

En el país, posterior a la independencia (1821), se constató una trayectoria incipiente e inconexa de disposiciones y acciones, dirigidas a las personas con discapacidad, que se fue fortaleciendo y articulando muy lentamente a partir de la segunda mitad del siglo xIx.

En etapas más recientes, fue en el último tercio del siglo pasado cuando las distintas áreas de la política social en el país se fortalecieron a partir de la promulgación de la Ley n..$^{\circ} 7600$, «Ley de igualdad de oportunidades para las personas con discapacidad» $(1996)^{2}$, legislación que favoreció el reconocimiento social de los derechos de esa población y tuvo de referencia lineamientos en ese ámbito, establecidos por organismos internacionales como la Organización Mundial de la Salud (OMS) y la Organización de Naciones Unidas (ONU).

Por otra parte, en algunos de los censos y recuentos de la población del país y en diferentes épocas, la variable «discapacidad» fue incluida y sistematizada, -aunque desde distintas definiciones y metodologías-, lo que demuestra el interés por contar con datos cuantitativos de ese segmento poblacional, información que se consigna en este trabajo.

${ }^{1}$ Las políticas públicas se estructuran dentro del Estado, pero cristalizan a partir de planteamientos y necesidades de diversos grupos. El concepto de política pública se entiende como producto de la acción de distintos agentes, en este caso organismos internacionales, grupos políticos, sindicales, comunales, sectores de la población con discapacidad o que conviven con personas en esa condición, líderes políticos y el Estado. Este asume distintas funciones, por ejemplo, como garante de la legislación vigente en el ámbito público y privado o como regulador y definidor de la inversión social destinada a esa población. El enfoque analítico propuesto por el neoinstitucionalismo histórico resulta de utilidad en el análisis de políticas sociales (Farfán, 2007: 87-124). Sobre los regímenes de bienestar, un trabajo de interés es el de Juliana Martínez (Martínez, 2007).

${ }^{2}$ El documento contiene 85 artículos y un transitorio (La Gaceta n. $\left.{ }^{\circ} 102,1996\right)$. El reglamento de la Ley fue emitido en 1998 (Decreto Ejecutivo n. ${ }^{\circ}$ 26831, 1998). 
En esta investigación, el análisis de la situación de las personas con discapacidad en Costa Rica, tanto en el pasado como en el presente, se inserta en una periodización que tomó en cuenta el papel jugado por distintos actores: el Estado, las organizaciones sociales de diferente conformación e iniciativas individuales. El estudio tomó en cuenta distintas fuentes de información, entre estas publicaciones de época, documentación del Archivo Nacional de Costa Rica e información censal.

En este trabajo, se estima que la diversidad es consustancial al ser humano. Las personas en condición de discapacidad son un segmento de esa diversidad. No obstante, a través del tiempo y en distintos contextos, la forma en que el conjunto de la población define, percibe y se relaciona con ese grupo ha sido diferente porque sus características, intereses y necesidades son distintas, esto debido a la interrelación que se da entre sus condiciones (físicas, sensoriales, intelectuales, mentales) y su entorno social (limitación en la actividad y restricción para la participación). La discapacidad es, en parte, un fenómeno sociocultural. Su construcción deviene de la interacción de diversos actores en un contexto sociocultural determinado, donde fueron diseñados modelos de atención y se definieron y ejecutaron políticas públicas específicas.

\section{ALGUNAS DISPOSICIONES INCIPIENTES RELACIONADAS CON LA POBLACIÓN CON DISCAPACIDAD EN COSTA RICA (1850- 1890): REGISTRO, CONFINAMIENTO, PENSIÓN DE GUERRA}

La etapa inmediata a la independencia en Costa Rica (1821) llevó a una transición entre las características propias del desarrollo colonial y la construcción de una sociedad nueva.

En este trabajo se parte del año 1850 porque hay consenso entre los estudiosos acerca de que en el lapso comprendido entre 1830-1850 culminó el tránsito de la economía colonial al capitalismo agrario, por medio del desarrollo del cultivo del café, actividad que modificó la estructura social, acentuó la desigualdad entre distintos sectores y profundizó las diferencias culturales compartidas hasta ese entonces ${ }^{3}$. Además, de forma paralela, a partir de 1850 , se sentaron las bases de la centralización política, etapa en que el Estado estaba encabezado por un grupo de comerciantes y productores-exportadores de café; el poder se sustentaba en el Ejército y las finanzas estatales dependían del aguardiente y el tabaco, monopolios organizados desde la colonia.

A partir de esas primeras décadas de vida independiente, se registran algunas prácticas, disposiciones y la creación de algunas instituciones, que de manera directa o tangencial se relacionan con las personas con discapacidad. De seguido se citan algunos hitos que destacaron en el período en estudio.

\footnotetext{
${ }^{3}$ Se comparte la periodización y el argumento que utiliza Botey (2013: 3) para el caso que estudia.
} 
Desde fines del período colonial, una de las prácticas desarrolladas para controlar la lepra fue el confinamiento de las personas y su aislamiento de los espacios habitualmente poblados en las comunidades. En la etapa independiente, también fue común el levantamiento de listas con los nombres, el estado civil y la condición económica de las personas afectadas por esa enfermedad, además de la contribución con limosnas para sostener su alimentación.

$\mathrm{Al}$ igual que otras enfermedades, la lepra puede presentar secuelas, ese es el caso de la afectación de las terminaciones nerviosas de manos y pies y provocar ceguera, discapacidades que agudizaban la situación de los portadores de esa enfermedad.

El constante contagio de los pobladores llevó a que en 1833 se estableciera un lazareto (Malavassi, 1998). Ese fue un primer esfuerzo para subsanar de alguna manera las necesidades de las personas afectadas por ese mal y por las secuelas de discapacidad que provocó.

Otra disposición con incidencia en la situación de las personas con discapacidades tuvo lugar cuando se aprobó la ley de reorganización del Ejército en 1850, institución que se fortaleció en las décadas siguientes y se mantuvo vigente hasta 1948, cuando fue abolida.

Su estructura contempló el ejército permanente (fuerzas acuarteladas), el ejército de operaciones (individuos entre los 18 y 50 años físicamente aptos) y la guardia nacional, a la que pertenecían todas aquellas personas que por aspectos físicos no podían ingresar al ejército de operaciones. Además, ese subgrupo sustituía al ejército de operaciones en caso de que este saliera de campaña (González y Solís, 1989: 66). Como se constata, desde 1850, en el Ejército se hizo referencia a la población con discapacidad y a la posición que debía y podía ocupar en sus filas.

El Código Militar de 1850 mantuvo las Ordenanzas Generales del Ejército, emitidas por el rey Carlos III de España en el siglo XVIII, que contempló el funcionamiento del Monte Pío, que resultó en un tipo de pensión por vejez e invalidez para los oficiales del Ejército de Costa Rica. Ese beneficio se conservó en el Código Militar de 1871, previa constancia de la condición de discapacidad del funcionario (Código Militar, 1871: 18).

A fines del siglo xix y en los años posteriores, estuvo vigente la Ley de Organización General del Ejército de la República de Costa Rica (1898). Esa legislación estableció que los individuos con «mala constitución física o defectos orgánicos justificados por certificación de los respectivos cirujanos del Ejército [...] quedaban exentos del servicio militar». Además, dispuso que la persona debía poseer «aptitud militar», definida en esa ley como «la capacidad intelectual y la condición sana y robusta del cuerpo» (Ley 14, 1898: x y XI).

Esas disposiciones apelan a un concepto de salud enfocado en la «normalidad» de las estructuras corporales y funciones fisiológicas de las personas; por lo tanto, la discapacidad fue una variable que condicionó la posibilidad de esos individuos de participar en el Ejército.

El Cuerpo de Sanidad Militar, formado por los cirujanos del Ejército, fue la autoridad encargada de calificar la aptitud física de los sujetos y de informar en caso de pensión. 
En caso de que la persona quedara inhabilitada temporal o permanentemente, debía plantear una solicitud para el trámite de su pensión, con cargo al Tesoro Público, dirigida a la Secretaría de Guerra por medio del Estado Mayor, general o divisionario o comandantes de provincia, en cuyas oficinas se preparaban los expedientes y se levantaban las pruebas. La Secretaría resolvía las solicitudes de la tropa y las peticiones de los oficiales se enviaban al Congreso (Ley 14, 1898: XI). El beneficio fue otorgado de forma diferenciada para los oficiales e integrantes de las tropas, con respecto al plazo y al monto concedido.

La ley de 1898 también contempló la existencia de un «Cuerpo de Inválidos» en el Ejército, influencia de la legislación militar española de 1717. Los miembros de ese grupo eran militares «inutilizados» por su participación en eventos bélicos.

Los militares costarricenses, afectados en la Campaña Nacional 1856-1857 contra los filibusteros estadounidenses de William Walker, podían solicitar y recibir la indemnización por ese motivo, tal y como se constata en la documentación de la época (Guerra y Marina, 1862-1907).

El conjunto de disposiciones indicadas en la legislación militar mantuvo su vigencia durante largo tiempo, hasta que el Ejército fue abolido en 1948.

Con respecto al número de personas con discapacidad en el período en estudio, solo destaca el censo de $1864^{4}$, pues hizo referencia a la condición mental y física de los habitantes de Costa Rica.

En las instrucciones para llenar la casilla de esa boleta censal que refiere a calidad «física y mental» se indicó: Bajo la expresión de "enteramente impedidos" se entienden aquellos que hayan perdido el uso de cualquiera otro órgano principal p.e. [sic] ambos pies o ambas manos, y por esta razón no están aptos para ganar su subsistencia. Se comprenden en los "imbéciles" aquellos que carezcan de sus facultades intelectuales por debilidad de ellas (mentecatos y fatuos), y en los dementes aquellos que no tengan el uso de ellas por excesiva irritación» (Censo, 1864: XL).

El registro de la «calidad física» de las personas incluyó a ciegos, sordomudos y enteramente impedidos. En el caso de la "calidad mental», la clasificación fue la de «dementes» e «imbéciles». Esos criterios remiten a la deficiencia.

En 1864, un 1,21\% de la población total de Costa Rica presentó alguna de las discapacidades indicadas, siendo la condición más connotada la sordomudez (39\%).

En el ámbito institucional, al finalizar la etapa en estudio, en Costa Rica se estableció el Asilo de Insanos en 1890 (CCSS, 2002: 4), destinado a albergar enfermos mentales y financiado por la Lotería Nacional, una institución que puso en marcha un modelo de atención para ese segmento de la población, respaldado por la comunidad de médicos del país.

En la primera década de su funcionamiento, para entonces denominado Asilo Chapuí (1896), habían sido atendidas 814 personas y registrado algunos diagnósticos: esquizofrenia paranoica, demencia precoz, idiotismo y consumo excesivo de alcohol (Rodríguez, 1974: 16). Esos pacientes eran declarados en «estado de enaje-

\footnotetext{
${ }^{4}$ La población total de Costa Rica registrada en ese censo fue de 120499 personas.
} 
nación mental» por el médico de pueblo, mientras que la autoridad superior certificaba esa declaración para su internamiento.

En aquella época, el doctor Vicente Lachner, convencido de la necesidad de ese hospital, argumentó el aumento en la cifra de enfermos e hizo referencia a las causas de las enfermedades mentales, señalando: «... más de la mitad de las enfermedades mentales entre nosotros se debe a la defectuosa selección matrimonial, inmensa responsabilidad que pesa sobre los padres de familia» (Lachner, 1902: 187), con lo que hizo referencia a la endogamia.

Un balance de la legislación y la institucionalidad, citada entre 1850-1890, muestra inicialmente una gestión a nivel municipal. A partir de 1850, se encuentran disposiciones y acciones a nivel nacional, que tienen relación con el contexto de centralización política. Ese es el caso del Ejército como institución estratégica y, por otra parte, el censo de 1864, que dio cuenta de la cantidad y características de los pobladores del territorio de Costa Rica.

Al cierre de esa etapa se registra la creación de un asilo para enfermos mentales (1890), ubicado en la ciudad capital, que, al igual que el lazareto fundado en 1833, tenía como propósito principal el confinamiento de las personas.

En ese período, las personas con discapacidad fueron caracterizadas bajo el enfoque de deficiencias y fueron objeto de la caridad de los grupos religiosos, la filantropía, la exclusión social y el aislamiento, acorde con el modelo tradicional de la época. Sí cabe destacar que el personal del Ejército, en particular la oficialidad, recibió el beneficio de pensión por invalidez, un antecedente importante de la legislación, que se puso en marcha para el conjunto de la población en la segunda mitad del siglo xx.

\section{LAS PERSONAS CON DISCAPACIDAD EN EL CONTEXTO DEL RÉGIMEN LIBERAL DE BIENESTAR EN COSTA RICA (1890-1940): REGISTRAR, EXCLUIR, REHABILITAR}

El cierre del siglo xix y la nueva centuria marcaron algunos cambios con respecto a la etapa anterior. Las disposiciones y la institucionalidad, creada en seis décadas en el país, dan cuenta de la continuidad de la participación de distintos actores sociales e individuales, pero con influencia -en las disposiciones tomadasde organizaciones internacionales, y con la convicción de los hacedores de la política pública en Costa Rica de estar asumiendo una dirección «científica» para el destino del país.

Desde mediados del siglo XIX, en distintos países, hubo interés en promover «encuentros internacionales», dirigidos a controlar enfermedades contagiosas y epidémicas. Esa fue la trayectoria de las Conferencias Sanitarias 5 inicia-

${ }^{5}$ Las Conferencias Sanitarias Internacionales fueron catorce (1851-1938). Algunas repúblicas americanas como Argentina, Brasil y Uruguay (1887) firmaron convenciones sanitarias. La Pri- 
das en 1851 y los Convenios Sanitarios posteriores, que lograron institucionalizar la salud pública.

Después de 1919, al término de la Primera Guerra Mundial, un volumen importante de hombres quedó con discapacidades físicas y mentales, razón por la cual se establecieron principios de rehabilitación médica en distintos puntos de la geografía mundial. Además, se crearon asociaciones de civiles discapacitados por accidentes en el trabajo, como lo fue la Federación de mutilados del trabajo en Francia (1921).

Esas condiciones fueron el contexto para que la Sociedad de Naciones ${ }^{6}$ celebrara el primer congreso de la Sociedad Internacional de Asistencia al Inválido (1929), donde las recomendaciones fueron la profilaxis para eliminar las causas de las discapacidades físicas, la obligación de informar sobre el nacimiento de los nińos deformes y afectados de cualquier lesión que los invalidara, la elaboración de un censo y la creación de escuelas especiales para la instrucción cultural y profesional de esa población (Miangolarra et al., 2003).

Buena parte de esas disposiciones tuvieron influencia en las acciones implementadas en Costa Rica, en particular porque la élite política y profesional del país, donde destacaron abogados y médicos, tuvo como referente los parámetros del desarrollo social y científico foráneo.

En esa etapa de 1890 a 1940, en Costa Rica, la financiación por parte del Estado para cubrir los ámbitos correspondientes a la salud, la educación, la vivienda, los servicios sociales, el empleo y el ingreso mínimo denota un crecimiento. Al respecto se señala sobre esos gastos del Estado que «con altibajos, desde un punto de partida del 4\% del gasto público total, como promedio del decenio 1870-1879, hasta un 28\% del gasto público total, como promedio del decenio 1920-1929» (Viales, 2008: 1411).

En ese lapso se mantuvieron algunas disposiciones e instituciones para las personas con discapacidad, que surgieron en el período anterior y que incluso permanecen vigentes en la actualidad. Ese fue el caso del Asilo Chapuí, institución que hoy se denomina Hospital Nacional Psiquiátrico Manuel Antonio Chapuí, vigente con parámetros distintos a los que le dieron su origen, actualmente insertos dentro de un modelo de atención para la salud mental, que reconoce los derechos humanos, previstos en la declaración de 1948 y también lo establecido en la declaración de Caracas en 1991, sobre los derechos de las personas con enfermedad mental.

mera Conferencia Internacional Americana se llevó a cabo en 1889 en Washington y siguiendo una de sus resoluciones en la Convención Sanitaria Internacional (1902) se estableció la Oficina Sanitaria Internacional (1902-1923) pasando a denominarse en 1923 Oficina Sanitaria Panamericana para obtener su nombre actual: Organización Panamericana de la Salud OPS (1958). Costa Rica participó en 1924 en la sétima conferencia sanitaria panamericana, encargada del estudio y la aprobación del Código Sanitario Panamericano, que con varias enmiendas se mantiene vigente.

${ }^{6}$ La Sociedad de Naciones (1919-1946) tuvo como propósito establecer las bases de la paz y restablecer las relaciones internacionales bajo los principios de cooperación, arbitraje y seguridad. Costa Rica formó parte entre 1920 y 1925. 
Otra disposición que se mantuvo vigente hasta 1948 fue el otorgamiento de pensiones por invalidez a los funcionarios del Ejército costarricense, quienes estuvieron involucrados en distintos acontecimientos bélicos, algunos de corta duración y otros de gran magnitud.

Uno de los más destacados fue el golpe de Estado de 1917, con importantes repercusiones dada la relativa estabilidad política del país. También, el conflicto fronterizo con Panamá en los meses de febrero y marzo en 1921, que culminó con la mediación del Gobierno de Estados Unidos para detener las hostilidades.

En la década del cuarenta, se abrió un ciclo caracterizado por la reforma social, la confrontación, la desobediencia civil y una espiral de violencia, que culminó con la Guerra Civil de 1948, situación que tuvo como desenlace la llegada de una Junta al Gobierno y la abolición del Ejército.

En el período 1890-1940, todos los funcionarios del Ejército afectados por las asonadas militares y los eventos bélicos podían tramitar su solicitud de pensión por invalidez, aportando la documentación dispuesta para ese propósito. Ese fue el caso de los afectados en el conflicto armado con Panamá (Serie Congreso y Serie Guerra y Marina, 1921-1924), quienes mencionaron como afectación más común problemas en los miembros inferiores o su condición de invalidez.

Los beneficios recibidos por los militares eran por una fracción de su salario, sujeto a revisión de las autoridades respectivas (el médico), y las peticiones podían ser rechazadas. El trámite de pensión podía durar unos meses o extenderse como plazo máximo hasta por dos años.

En esa época, la condición de discapacidad se asoció con la deficiencia, condición que calificó al sujeto como inhabilitado para el trabajo por su situación de invalidez, concepto vigente en la legislación, las instituciones y actores sociales.

La ley de accidentes de trabajo de 1925 también marcó un hito en la historia costarricense, pero en aquellos años solo aseguró a un fragmento de los trabajadores. No obstante, será el inicio del actual Instituto Nacional de Seguros.

Una de las novedades en el período 1890-1940 fue el desarrollo de la Enseñanza Especial, favorecido por la articulación de las entidades que se ocupaban de los asuntos de salud y educación en el país.

A fines del siglo XIX, la reforma educativa promovió la centralización, secularización y actualización del sistema educativo a cargo de la Secretaría de Instrucción Pública (1885). De igual forma, para mejorar las condiciones de higiene y salud de la población costarricense, tuvieron importancia la Facultad de Medicina (18951940) y más adelante la Secretaría de Salubridad Pública (1922).

En esa etapa, esos dos ámbitos de la política pública se articularon y eso favoreció que el sistema educativo se constituyera en la base sobre la cual se estructuró la salud pública.

El resultado de ese vínculo favoreció la higienización en las escuelas, tarea que consistió en la revisión médica, el tratamiento dental y la higiene en la infancia (Palmer, 2009: 408). Ese esfuerzo conjunto propició la creación el Departamento Sanitario Escolar (1914) y el Reglamento del Cuerpo Médico Escolar e Inspección Médica e Higiénica de los establecimientos de Instrucción Pública. Esas dependencias tuvieron a cargo las labores de observar y registrar las particularidades de 
la población escolar costarricense en una cobertura de carácter nacional y uniformando los formularios médicos.

El estado sanitario de las escuelas y la salud de los estudiantes a cargo de esas instancias se vieron reforzados con la promulgación de la Ley sobre Protección de la Salud Pública (1923), que estableció la obligación de los jefes de Sanidad de hacer dos visitas anuales a las escuelas para inspeccionar su estado sanitario y la condición física e intelectual de los escolares, en caso de ausencia del médico escolar (Ley 52, 1923). En 1926 se emitió el Reglamento de Inspección Médica de las Escuelas, cuya aplicación pasó a estar a cargo de la nueva Subsecretaría de Higiene (Decreto Ejecutivo 2, 1926).

Esa Inspección Médica tuvo por objetivos la protección de los niños contra toda causa de enfermedad, el diagnóstico de enfermedades agudas o crónicas, el tratamiento para los niños pobres y la «observación de los escolares física o intelectualmente anormales» (Campos, 2015: 7).

El médico escolar sometía a los niños a un examen de su constitución física y mental. Completaba una tarjeta con información sobre datos antropométricos, medidas de agudeza visual y auditiva, examen de la boca, la faringe, la nariz, los dientes, la columna, el corazón, los pulmones. Además, registraba antecedentes hereditarios, familiares y el estado del desarrollo mental del niño.

En esa etapa, existió interés, de los médicos, intelectuales y pedagogos, por registrar los aspectos físicos, fisiológicos y mentales de la población escolar, tanto con el propósito de incidir científicamente en la disminución de las tasas de morbilidad y mortalidad infantil como también por la necesidad de mantener las bases de una ciudadanía «apta física y mentalmente» (Campos, 2015: 8).

Ese interés se mantuvo cuando se levantó el censo de población en el año $1927^{7}$, el primer censo del siglo xx, que incorporó la variable «condición mental y física». Ese registro mostró solo al 0,37\% de la población con alguna de las siguientes condiciones: sordera, ceguera, mudez y demencia. Ese resultado fue afectado tanto por la omisión calculada en el censo como por el diseño del ítem en la boleta y la negación en la declaración.

En 1927 la mayoría de los habitantes residían en la región central y ahí fue donde se ubicó la mayor parte de la población con discapacidad, en particular, en Cartago y Heredia. Las personas con sordera obtuvieron el mayor porcentaje, un 51\% con respecto a otras discapacidades (Campos, 2013: 23).

Algunos datos socioculturales y laborales constatan que del conjunto de la población del país que sí sabía leer y escribir en aquella época, un $0,2 \%$ presentó alguna discapacidad y, de quienes se declararon analfabetos, una cifra cercana al $1 \%$. Por otra parte, de la población inscrita en primaria un $0,2 \%$ presentó alguna discapacidad y, de quienes asistieron a la secundaria un $0,1 \%$ tuvo esa condición. Esos datos refieren la escasa incorporación de ese segmento al sistema educativo. Acerca

\footnotetext{
${ }^{7}$ El total de la población registrada en Costa Rica en ese año fue de 471524 personas.
} 
de las ocupaciones, alrededor de un 1\% de población con discapacidad se ubicó en el sector agrícola, de transporte o en el de personas sin oficio (Campos, 2013: 22-23).

Los registros escolares y la información censal dieron cuenta a los encargados de la política pública de las condiciones físicas y mentales de la población. No fue casual que, en el Código de la Infancia en 1932, se vislumbrara la necesidad de crear establecimientos para nińos «anormales» o con «debilidad mental» (Campos, 2015: 9).

A fines de esa década, con la creación del departamento de Higiene Mental en el Ministerio de Salubridad Pública, a cargo del doctor Fernando Quirós Madrigal (1907-1961) y, en especial, del profesor Fernando Centeno Güell (1908-1993), quedó claro el interés por fundar un centro para menores con discapacidades.

En 1940 Centeno Güell presentó al Poder Ejecutivo un proyecto para la creación de una sección de enseńanza especial del niño, propuesta acogida y que dio fundamento a la creación de la Escuela de Enseñanza Especial ese año. En el decreto se afirmó: «El Estado no debe permanecer indiferente a la suerte de estos niños, sino más bien procurar su mejoramiento de acuerdo con los recursos que indica la ciencia médica y la psicología» (Decreto Ejecutivo 10, 1940: 338).

En esa institución se siguieron tendencias en el aprendizaje provenientes de escuelas españolas, belgas, alemanas y estadounidenses, se trabajó con terapia ocupacional y se emplearon aparatos electrofónicos y procedimientos para la educación de la vista, el oído y el tacto (Campos, 2015: 15).

La deficiencia siguió presente como criterio en el modelo de atención, pero la Escuela de Enseñanza Especial, hoy Centro Nacional de Educación Especial Fernando Centeno Güell, planteó la rehabilitación para sus alumnos.

En el período en estudio, diversos grupos como el cuerpo de médicos, algunos órganos de gobierno, como la Secretaría de Instrucción Pública y la de Salubridad Pública, y algunos educadores abogaron por acciones y disposiciones, que mostraron la coexistencia en el tiempo del modelo de atención tradicional, centrado en el aislamiento y la exclusión, junto con el modelo médico-pedagógico, cuyos ejes fueron la rehabilitación y la integración.

\section{EL RÉGIMEN ESTATAL PROTECCIONISTA DE BIENESTAR Y LAS PERSONAS CON DISCAPACIDAD (1940-1985): REHABILITAR, PROTEGER, INTEGRAR}

En la etapa 1940-1980, el Estado costarricense profundizó su intervención en la prestación directa de servicios a la población, siendo las personas con discapacidad un grupo destinatario de esa asistencia. Además, el país contó con directrices promulgadas por organismos supranacionales en el ámbito de la discapacidad.

Una de las consecuencias sociopolíticas de las conflagraciones mundiales fue el surgimiento de órganos supranacionales para velar por un orden económico, social y político en los países. Desde allí emanaron directrices en diferentes ámbitos: salud, trabajo, educación, derecho y protección social. Otra consecuencia social de las dos guerras mundiales fue el gran volumen de población afectada por disca- 
pacidad y la dificultad para incorporarla al trabajo, razón por la cual se establecieron directrices en ese sentido, en especial en la rehabilitación. También los accidentes laborales movieron el interés por asociar a los afectados y llamar la atención de esos organismos, especialmente la ONU (1945), la Organización Internacional del Trabajo OIT (1946) y la OMS (1948).

Desde esos órganos, emanaron disposiciones universales y convenciones internacionales, que dieron a conocer derechos y deberes, protección y prevención, uniformaron conceptos, reglas, disposiciones y formas de atención que por ser inclusivas cubrieron a la población con discapacidad y fueron acogidas por Costa Rica. Entre estas, Declaración Universal de los Derechos Humanos (1948); Convención sobre derechos políticos de la mujer (1953), Convenio relativo a la discriminación en materia de empleo y ocupación (1960), Convención de los Derechos del Niño, 1989 (CONAPDIS, 2020).

En la década de 1950, esos organismos prestaron especial atención a las personas con deficiencias visuales en los países en desarrollo y recomendaron la exoneración de impuestos a los artículos de las personas invidentes, impulsaron la rehabilitación y fomentaron programas de rehabilitación en el mundo.

En el siguiente decenio, la ONU creó mecanismos de supervisión de los programas de rehabilitación en el mundo y en el artículo 19 inciso «d» de la Declaración sobre el Progreso y el Desarrollo Social (1969) hizo referencia a la prestación de servicios médicos, de seguridad y de bienestar social.

En los años setenta, se emitió la Declaración de los Derechos del Retrasado Mental (1971).

También, la ONU promovió la rehabilitación (1973), la eliminación de barreras físicas y arquitectónicas (1975), la Clasificación Internacional de Deficiencias, Discapacidades y Minusvalías (1980) y proclamó el Año Internacional de los Impedidos (1981).

Esa información muestra cambios en los conceptos para designar a ese segmento de la población, unos más restrictivos y otros un poco más inclusivos. Entre estos se encuentran retrasados, impedidos, inválidos, minusválidos, relacionados con los modelos de atención vigentes.

$\mathrm{La}$ incidencia de las disposiciones internacionales en Costa Rica se puede constatar durante la epidemia de poliomielitis (1953-1954). En esa ocasión, en el Hospital San Juan de Dios se estableció un pabellón de rehabilitación para niños, que contó con personal capacitado enviado por la OMS (Murillo, 1992: 71-72). En ese momento también se contó con el apoyo de médicos, fisioterapistas y técnicos en prótesis de varios países del continente, quienes contribuyeron con los ortopedistas nacionales.

Con posterioridad a esa epidemia, el doctor Humberto Araya impulsó la cooperación internacional para fortalecer la rehabilitación y, en consecuencia, la creación del Patronato Nacional de Rehabilitación (PANARE, 1966), instancia creada para la atención de ese grupo (Murillo, 1992: 72). Además, otros hospitales del país dieron el servicio de rehabilitación y fisioterapia, incluido el Hospital de Niños (1964).

Esas acciones se reforzaron con la fundación del Centro Nacional de Rehabilitación (CENARE, 1977), institución dedicada a la atención de personas con dis- 
capacidad neuromusculoesquelética, que formó parte de la Caja Costarricense de Seguro Social (CCSS) ${ }^{8}$.

Por otra parte, la Asociación Amigos del Ciego (1955) y el Patronato Nacional de Ciegos (PANACI, 1957) fueron instancias que nacieron para la protección, habilitación y rehabilitación de la persona con ceguera (Ley 2171, 1957).

La ampliación en la cobertura de escuelas de enseñanza especial ${ }^{9}$ fue reforzada en el período en estudio con la labor del Centro de Educación Especial Neuro-psiquiátrica Infantil (1968). En los años setenta, el Ministerio de Educación Pública desarrolló el programa de aulas diferenciadas (1974), luego llamadas aulas integradas (1979), que operaron como secciones en escuelas regulares (Murillo, 1992).

En 1973, el Consejo Nacional de Rehabilitación y Educación Especial (CNREE), hoy Consejo Nacional de Personas con Discapacidad (CONAPDIS, 2015), fue una instancia que atendió demandas de ese segmento, coordinó la colaboración de órganos no gubernamentales y de apoyo externo y hoy es la entidad rectora en materia de discapacidad.

Acerca del sistema de pensiones, la universalización del Seguro Social desde la década del setenta favoreció la ampliación en la asignación de pensiones denominadas de «invalidez» para las personas con discapacidad, sujetas a requisitos establecidos por la Caja Costarricense de Seguro Social.

Con respecto al recuento de población, cuando se levantaron los censos de los ańos 1950, 1963, 1973 y 1984, en todos se hizo referencia a las personas con discapacidad, pero los criterios fueron diferentes al clasificar a la población por inactividad (1950) o condición de actividad económica y, además, se llevó a cabo de forma agregada, tal y como se aprecia en la tabla I.

En esos registros, la discapacidad fue considerada como una condición que inhabilitaba para el trabajo, las personas eran catalogadas como inactivas económicamente y, además, clasificadas junto a otros grupos considerados inactivos: adultos mayores y niños. También eran considerados enfermos. Ese fue el caso de «los enfermos mentales». Además, fueron incluidas junto a segmentos marginales: mendigos, vagabundos y antisociales (Campos, 2013: 7).

Por otra parte, en el lapso comprendido entre 1950 y 1980, estuvo vigente la Clasificación Internacional de Enfermedades (CIE) emanada desde la OMS en diferentes revisiones. No fue hasta 1980 cuando ese ente aprobó el manual de la Clasificación Internacional de Deficiencias, Discapacidades y Minusvalías (CIDDM, 1980), donde definió la deficiencia como pérdida o anormalidad de una estructura o función psicológica, fisiológica o anatómica y la discapacidad como toda restricción o ausencia de capacidad de realizar una actividad debida a una deficiencia.

La vigencia de esas disposiciones internacionales explica, en parte, la asociación de la discapacidad con la enfermedad y con la deficiencia, aspectos que se

\footnotetext{
${ }^{8}$ Por aplicación de la Ley 5349 del 24 de setiembre de 1973 se hizo el traslado a la CCSS.

9 Se estableció con la Ley Fundamental de Educación (Ley 2160, 1957). El artículo 27 fue reformado con la Ley 7600 del 2 mayo de 1996.
} 


\begin{tabular}{|c|c|c|c|}
\hline \multicolumn{4}{|c|}{ TABLA I. CLASIFICACIÓN DE LA POBLACIÓN CON DISCAPACIDAD EN LOS CENSOS (1950-1984) } \\
\hline FECHA & VARIABLE & CAtegoría & Dato \\
\hline 1950 & $\begin{array}{l}\text { Población } \\
\text { económi- } \\
\text { camente } \\
\text { inactiva }\end{array}$ & $\begin{array}{l}\text { Otro estado: incluyó a personas retiradas por edad, incapaci- } \\
\text { dad, recluidas en un penal, en un asilo de caridad o enfer- } \\
\text { medades mentales, los que tenían ceguera o parálisis. }\end{array}$ & $2 \%$ de la PEI \\
\hline 1963 & \multirow{3}{*}{$\begin{array}{l}\text { Condición } \\
\text { de actividad } \\
\text { económica }\end{array}$} & $\begin{array}{l}\text { Desocupados. Incluyó estudiantes, personas en oficios } \\
\text { domésticos, pensionados, rentistas, internados en institucio- } \\
\text { nes, enfermos físicos y mentales. }\end{array}$ & $\begin{array}{l}\text { Los enfermos } \\
\text { físicos y mentales } \\
\text { representaron el } 1 \% \\
\text { de los registrados } \\
\text { como desocupados. }\end{array}$ \\
\hline 1973 & & $\begin{array}{l}\text { Otro. Incluyó personas con ceguera, parálisis, deficiencias } \\
\text { físicas, sin ocupación. Niños que terminaron la escuela, no } \\
\text { trabajaban, ni buscaban trabajo, personas mayores de } 65 \\
\text { ańos. También mendigos, vagabundos y antisociales. }\end{array}$ & $\begin{array}{l}\text { No se desagregó en } \\
\text { el censo. }\end{array}$ \\
\hline 1984 & & $\begin{array}{l}\text { Incluyó las anteriores registradas en el censo de 1973, más } \\
\text { los que estaban en la cárcel, convento, asilo y hospital. }\end{array}$ & $\begin{array}{l}\text { No se desagregó en } \\
\text { el censo. }\end{array}$ \\
\hline
\end{tabular}

Elaboración propia. Fuente: censos de población de Costa Rica 1950, 1963, $1973,1984$.

pueden observar en los criterios de clasificación empleados en los censos de población de Costa Rica entre 1950 y 1984.

En el transcurso del período en estudio, órganos estatales, civiles e internacionales estuvieron involucrados en la atención de la población con discapacidad. También participaron médicos, terapeutas, enfermeros, microbiólogos, trabajadores sociales, educadores y abogados, así como la misma población objeto de atención. Todos fueron actores responsables de prácticas, conceptos y políticas dirigidos a ese sector.

La trayectoria institucional reseñada muestra el énfasis en el modelo rehabilitador para la atención de las personas con discapacidad, un modelo que tuvo su origen en los mutilados de la Primera y la Segunda Guerra Mundial, donde la discapacidad radicó en el sujeto que tuvo un daño - una deficiencia- limitado en su capacidad y, por tanto, fue necesario restablecer y rehabilitar al individuo para integrarlo a la sociedad. Para eso fue preciso eliminar u ocultar la diferencia. Además, ese modelo propició políticas públicas de compensación, como la asistencia y la seguridad social. 


\section{LA SITUACIÓN DE LAS PERSONAS CON DISCAPACIDAD EN EL TRÁNSITO DEL RÉGIMEN ESTATAL-PROTECCIONISTA DE BIENESTAR A LA FASE DE AJUSTES (1985-SIGLO XXI): RECONOCIMIENTO, AUTONOMÍA, DERECHOS}

Hacia el último quinquenio del siglo xx, Costa Rica contó con directrices internacionales y legislación nacional, que concebían la discapacidad en tres dimensiones: deficiencia, limitación en la actividad y restricción en la participación e impulsaron un modelo social sustentado en la igualdad de oportunidades basada en derechos, autonomía, capacidad y respeto a la diversidad. Resulta un fenómeno complejo en la interacción entre el organismo humano y las características de la sociedad donde vive ${ }^{10}$. Con el modelo inclusivo de ciudadanía, se aseguraron garantías plenas de sus derechos (Blanco y Sánchez, 2006: 39-40). En ese desarrollo la coexistencia de modelos no fue una excepción.

De los años ochenta al siglo XXI, Costa Rica acogió varias disposiciones de la ONU, entre estas, principios para la protección de los enfermos mentales y la mejora de la atención de la salud mental (1991), la declaración del día 3 de diciembre como Día Internacional de las Personas con Discapacidad (1992) y Normas Uniformes sobre la Igualdad de Oportunidades para Personas con Discapacidad (1993). Esa última disposición fue la base para la cooperación técnica y económica, incorporando la perspectiva de los derechos humanos (Blanco y Sánchez, 2006: 40).

También lo dispuesto por la Organización de Estados Americanos (OEA) fue un esfuerzo regional para poner en marcha políticas en el área, enfatizando en los derechos humanos y la eliminación de la discriminación; un ejemplo fue el Programa de acción para el decenio de las Américas por los derechos y la dignidad de las personas con discapacidad (2006-2016), el cual quedó ratificado en Costa Rica (CONAPDIS, 2020).

En las últimas décadas del siglo xx en Costa Rica continuó la gestión del CNREE, que se vio acompañada de las disposiciones establecidas en los planes nacionales de gobierno y de la labor de la rectoría emanada de los ministerios e instituciones involucrados con la atención y demandas de la población con discapacidad.

La promulgación en Costa Rica de la Ley 7600 Ley de Igualdad de Oportunidades para las Personas con Discapacidad (1996) constituyó el marco legal para atender las necesidades de esa población y para la formulación de políticas públicas. Esa ley buscó la igualdad de oportunidades, la eliminación de la discriminación y propuso la inclusión, propiciando el acceso a la educación, al trabajo, a los servicios de salud, a los medios de transporte, información y comunicación, estableciendo reformas en códigos y leyes vigentes, por ejemplo, al Código Penal, Civil y de Familia, a la Ley Fundamental de Educación y Ley General de Salud (Ley 7600, 1996).

${ }^{10}$ La definición se encuentra en la página web de la Organización Mundial de la Salud OMS en temas de salud. 
La legislación del año 1996 y las directrices impulsadas desde los organismos internacionales en el último tercio del siglo xx fueron el marco apropiado para mejorar las condiciones para la población en condición de discapacidad en el nuevo siglo.

Las políticas nacionales en materia de discapacidad fueron articuladas en varios ejes: políticas para la institucionalidad, comprometidas con la población con discapacidad; políticas para la accesibilidad y la calidad de vida; políticas para la participación plena y para la investigación y cooperación. Sus principios fueron igualdad, no a la discriminación, participación, autonomía personal y accesibilidad. Esas políticas favorecieron la conformación de Comisiones Institucionales en Materia de Discapacidad (CIMAD), instancias que articularon el funcionamiento de las instituciones públicas.

La legislación posterior (tabla II) a la emisión de la Ley de Igualdad de Oportunidades dio cuenta de la aprobación de nuevos convenios internacionales, así como del fortalecimiento de la multiplicidad de ámbitos que garantizaron los principios antes citados, mediante las disposiciones emitidas a nivel nacional. En esa promulgación cabe destacar la creación del Consejo Nacional de Personas con Discapacidad (CONAPDIS, 2015), instancia rectora en la actualidad, que tuvo como antecedente al CNREE (1973). La denominación del ente rector en dos momentos distintos denota el cambio en el modelo de atención y en la definición de discapacidad.

\begin{tabular}{|c|c|c|}
\hline AÑo & LEY & Título de LA Ley \\
\hline 1999 & 7948 & $\begin{array}{l}\text { Aprobación de la Convención Interamericana para la eliminación de todas } \\
\text { formas de discriminación contra las personas con discapacidad }\end{array}$ \\
\hline 2008 & 8661 & $\begin{array}{l}\text { Aprobación de la Convención sobre los Derechos de las personas con discapa- } \\
\text { cidad y su protocolo }\end{array}$ \\
\hline 2010 & 8822 & Creación de las Comisiones Municipales de discapacidad COMAD \\
\hline 2010 & 8862 & $\begin{array}{l}\text { Inclusión y protección laboral de las personas con discapacidad en el sector } \\
\text { público }\end{array}$ \\
\hline 2012 & 9049 & $\begin{array}{l}\text { Ley de reconocimiento de Lenguaje de Seńas Costarricense LESCO como } \\
\text { lengua materna }\end{array}$ \\
\hline 2013 & 9171 & Creación de comisiones institucionales sobre accesibilidad y discapacidad CIAD \\
\hline 2015 & 9303 & Creación del Consejo Nacional de personas con discapacidad CONAPDIS \\
\hline 2016 & 9379 & Promoción de la Autonomía personal de las personas con discapacidad \\
\hline 2018 & 9616 & $\begin{array}{l}\text { Reforma Ley de Igualdad de Oportunidades para las Personas con Discapacidad } \\
\text { en sus artículos } 41 \text { y } 54\end{array}$ \\
\hline 2019 & 9697 & $\begin{array}{l}\text { Reforma artículo } 51 \text { de la Constitución Política para garantizar la protección } \\
\text { especial del Estado a las personas con discapacidad }\end{array}$ \\
\hline 2019 & 9714 & Adición del capítulo Viii, acceso a la justicia, al título II de la Ley n. ${ }^{\circ} 7600$ \\
\hline 2019 & 9739 & $\begin{array}{l}\text { Reformas para la inclusión al deporte y la recreación de las personas con dis- } \\
\text { capacidad }\end{array}$ \\
\hline
\end{tabular}




\begin{tabular}{ccl}
\hline 2019 & 9793 & $\begin{array}{l}\text { Reforma al Instituto del Deporte y Recreación (ICODER) y su Régimen Jurídico } \\
\text { y de Impuestos sobre Cigarrillos y Licores para Plan de Protección Social, para } \\
\text { la inclusión al deporte y la recreación de las personas con discapacidad }\end{array}$ \\
\hline 2020 & 9821 & $\begin{array}{l}\text { Otorgamiento de un segundo bono familiar de vivienda para personas con } \\
\text { discapacidad }\end{array}$ \\
\hline
\end{tabular}

Elaboración propia. Fuente: Costa Rica. Sistema Nacional de Legislación Vigente. Procuraduría General de la República.

Una aproximación a la situación reciente de la población en condición de discapacidad se plantea desde los datos que ofrecen los censos del país en los años 2000 y 2011.

Esos censos se localizan en una etapa de descenso drástico del crecimiento demográfico y después por una estabilidad relativa. Ello fue debido a un proceso relacionado con una baja en la tasa de natalidad y un descenso sostenido de la mortalidad, donde el envejecimiento demográfico y el aumento en la esperanza de vida son características en ese momento.

El contexto de envejecimiento demográfico, en el que ubican los registros del ańo 2000 y 2011, mostraron asociación con una mayor prevalencia de deficiencias y discapacidades. El subgrupo de población mayor de ochenta años se ha caracterizado por una mayor prevalencia de discapacidades físicas y mentales, retirados de la fuerza laboral, viudos y dependientes (Ramírez, 1998).

En el censo del $2000^{11}$, se incluyó un ítem sobre discapacidad. Ese hecho respondió a la necesidad de información del CNREE y a la ampliación de oportunidades según la Ley de Igualdad de Oportunidades para las personas con discapacidad en Costa Rica (1996).

Además, en ese censo se definió la discapacidad como cualquier deficiencia permanente, física, mental o sensorial, que dificulte a las personas realizar actividades cotidianas de manera independiente. Se estableció que las deficiencias podían ser de origen congénito (desde el nacimiento) o adquiridas (por enfermedad o accidente). Se registraron ceguera parcial o total, sordera parcial o total, retraso mental, parálisis y amputación, trastorno mental y otras ${ }^{12}$.

Esas categorías de clasificación fueron más amplias si se comparan con las usadas en otros registros, pero el concepto de discapacidad empleado se refirió solo a la deficiencia, definida como la pérdida o anormalidad de una estructura, función fisiológica, psicológica o anatómica, siguiendo lo dispuesto en la Clasificación Inter-

${ }^{11}$ La población total del país en ese año fue de 3810179 personas.

${ }^{12}$ La ceguera parcial o total y la sordera parcial o total consiste en la pérdida de la capacidad visual o auditiva respectivamente; el retardo mental resulta de las dificultades significativas en el funcionamiento intelectual y el aprendizaje de conceptos y actividades prácticas. Parálisis y amputación comprenden la pérdida, parálisis o dificultad de funcionamiento o movilidad de una o varias partes del cuerpo; trastorno mental es una enfermedad que provoca serios problemas de adaptación y comportamiento social de las personas. En «otras» discapacidades se incluyó la enfermedad pulmonar obstructiva crónica, la fibrosis quística, el labio leporino, la hemofilia, la mudez y la epilepsia (Censo, 2000). 
nacional de Deficiencias, Discapacidades y Minusvalías (CIDDM, 1980). Aunque la Ley 7600 (1996) consideró la discapacidad en relación con las deficiencias, con las limitaciones y con la restricción en la participación, esa definición no fue usada en el censo del año 2000.

En el año 2000, quienes presentaron algunas de las discapacidades indicadas en la boleta censal constituían el 5,35\% de la población; un 93\% se declararon sin ninguna discapacidad y un $1 \%$ fue declarada como ignorada. En esa fecha, las personas con discapacidad visual fueron quienes presentaron el mayor porcentaje con un 31\% (Campos, 2013: 8).

En relación con los grupos de edad, la población mayor de 60 años fue la que obtuvo el porcentaje más alto con un $21,6 \%$. La diferencia por sexos no fue significativa.

La distribución en el territorio nacional sí marcó diferencias. Las provincias de Puntarenas (7\%), Guanacaste $(6,2 \%)$ y Limón $(6,1 \%)$, provincias costeras y alejadas de la capital, fueron las que presentaron los porcentajes más altos. Las otras provincias se acercaron al promedio nacional de discapacidad (Campos, 2013: 12).

En esa fecha censal, la proporción de personas con discapacidad que sabía leer y escribir fue de un 5\%, mientras que las analfabetas constituían un 11,6\%. Con respecto al nivel de instrucción los individuos inscritos en primaria, representaron el 6,5\%, aunque también hubo acceso a otros niveles, pero en menor proporción (Campos, 2013: 22).

A fines del siglo $\mathrm{xx}$, la población con discapacidad que formó parte de la fuerza laboral estaba empleada en el sector agropecuario $(7,7 \%)$ y un $5 \%$ en oficios no calificados, lo que ubicó a esas personas, en un nivel bajo en el extremo de la estructura ocupacional.

Para el segmento poblacional en estudio, se observó una mayor proporción de discapacidad en mujeres como cabezas de hogar (10,3\%).

Sobre la estructura de los hogares de las personas con discapacidad, se constató que los hogares de tipo unipersonal representaron un 13\%, seguidos de los hogares colectivos (10,7\%), luego un $9,9 \%$ en los no conyugales y un $6,3 \%$ en los conyugales. Esos datos denotan la debilidad de los lazos de parentesco en esa población. Dentro de ese conjunto de hogares, se identificaron como más vulnerables los que estaban en condición de hacinamiento (7\%), donde la proporción de discapacidad fue de un $8 \%$ entre los encabezados por mujeres y de un $6 \%$ aquellos a cargo de hombres (Campos, 2013: 24).

El primer censo del siglo Xxi en Costa Rica tuvo lugar en el año $2011^{13}$. En esa ocasión, se contó con un módulo estándar dispuesto por la OMS -Grupo Washington-. En coordinación con el Instituto Nacional de Estadística y Censos INEC y el CNREE, se preparó el ítem sobre discapacidad.

Ese ítem mostró ocho alternativas de marcado múltiple. El encabezado ponía «Tiene alguna limitación permanente...» y las opciones fueron estas: ¿para ver aun

\footnotetext{
13 La población total registrada en ese censo fue de 4301712 personas.
} 
con los anteojos o lentes puestos?; ¿para oír?; ¿para hablar?; ¿para caminar o subir gradas?; ¿para utilizar brazos o manos?; ¿de tipo intelectual? (retardo, síndrome de Down, otros); ¿ ¿de tipo mental? (bipolar, esquizofrenia, otros), ninguna de las anteriores (INEC, 2011: 147).

Las opciones que se ofrecen en la boleta censal refieren al carácter permanente y a la limitación como la condición que define la discapacidad. Aunque se constata el uso de la herramienta Clasificación Internacional del Funcionamiento de la Discapacidad y la Salud (CIF, 2001) emitida por la OMS, una propuesta que incorpora el ámbito social y no solo el médico sanitario, en la boleta del censo del 2011 en Costa Rica se enfatizó solo en la limitación.

Los datos de ese censo (Pérez, 2012) fueron procesados por el CNREE. En este trabajo se destacarán algunos de esos resultados. El primer dato que mostró ese estudio denotó que la discapacidad más significativa en la población, tanto en las personas que tienen discapacidad (41,7\%) como a nivel nacional $(5,8 \%)$, fue la visual. Ese resultado incluyó a personas ciegas, pero también a aquellas con baja visión que, aun con lentes o anteojos, es manifiesta la limitación visual. En segundo lugar, se ubicó la limitación de movimiento con un $23,3 \%$ en las personas con discapacidades y un 1,6\% en la población total del país. La limitación para oír ocupó el tercer lugar con un $11,7 \%$ en las personas con discapacidad y un $0,7 \%$ en el total de las personas del país (Pérez, 2012: 5).

Con respecto al aseguramiento de la población en edad laboral (18 a 65 años), en ese estudio del CNREE, se sustentó que entre un $41 \%$ y un $75 \%$ de personas con discapacidad eran asegurados por un familiar o tienen un seguro o pensión para su manutención. Además, en el estudio se demuestra la condición de asalariado(a), cuyo porcentaje estuvo entre un 5\% y 30\% (Pérez, 2012: 7).

Los datos ofrecidos por la fuente de información consultada señalan que un $46,4 \%$ de la población con discapacidad en edades entre 18 y 65 años estaba trabajando o buscaba trabajo.

Con respecto a la asistencia a un centro educativo, los datos de la fuente señalada indican que un $74,6 \%$ de los niños y niñas con discapacidad asistían a uno, pero solamente un $57,6 \%$ de adolescentes estaban en secundaria, mientras que a la Universidad solo asistían el 24,8\% de los que tenían edades entre los 18 y 25 años.

Acerca de las condiciones de tenencia de la vivienda, esos datos indican que la posesión de casa propia en las personas con discapacidad fue mayoritaria $(76,72 \%)$. De ese $76,72 \%$, un $68,37 \%$ es casa totalmente pagada y el resto (apenas un $8,35 \%$ ) es propia, pero aún la están pagando. El 12,63\% de las personas con discapacidad viven en casas alquiladas. También se registró que 6675 personas con discapacidad viven en precarios ( $1,47 \%$ de la población total con discapacidad) y 5033 personas con discapacidad viven en viviendas colectivas, que pueden ser hospicios, albergues, cárceles o conventos. Según los datos del censo 2011, un 54,7\% de la población con discapacidad vive en viviendas cuya condición es buena; un $32,1 \%$ es regular, y un 12,0\% fue considerada mala (Pérez, 2012: 15-16).

Respecto a la población adulta mayor, los datos refieren que existían 311712 personas mayores de 65 años. De ellas, 127346 presentaban al menos una discapacidad. Eso representa aproximadamente un 3\% de la población total. Pero en la 
población de 65 años o más, es de aproximadamente 40,85\%. Además, solo el 40\% recibe pensión o trabaja por cuenta propia. De la población pensionista, el 51,2\% está asegurada por el Estado, lo que podría indicar una condición económica baja para la subsistencia (Pérez, 2012: 20).

Los resultados de los censos del 2000 y el 2011 con respecto al predominio de la discapacidad visual en el conjunto de la población llevaron al desarrollo de estudios que denotaron como causas principales de esa situación la catarata no operada y la retinopatía diabética (Acevedo et al., 2016: 1-37).

Los resultados generales de la primera encuesta nacional de discapacidad llevada a cabo en Costa Rica en el año 2018 y publicada en el 2019 refieren distintos aspectos de la situación actual de la población con discapacidad (INEC y CONAPDIS, 2019).

De acuerdo con esos datos, correspondientes al total de personas de 18 ańos y más del país, un 18,2\% estaban en condición de discapacidad, de los cuales, un $14,4 \%$ tenían una condición severa y un 3,8\% leve.

El contraste entre las distintas regiones del país destacó a tres de ellas con los valores más altos en discapacidad: el Pacífico Central, con un 24\%, seguido de la zona Brunca, en el sur del territorio de Costa Rica, con un 22,5\%; y la zona Chorotega, correspondiente a la totalidad de la provincia de Guanacaste, con un 21,6\%. Las diferencias también se observan en la ubicación de las personas con discapacidad por zona urbana $(74,1 \%)$ y rural $(25,9 \%)$.

Por otra parte, el 99, 6\% de la población con discapacidad lee y escribe, pero el 95,5\% no recibió apoyo educativo, de equipo o psicopedagogía. Con respecto a la educación formal, el 7,4\% no tenían ningún nivel de instrucción, un 19,6\% no tenía la primaria completa y solo el $17 \%$ había alcanzado la educación superior.

La condición de actividad mostró al 56,4\% fuera de la fuerza de trabajo, situación relacionada con la salud $(50,4 \%)$, con el hecho de que no les daban trabajo por distintas razones $(22,8 \%)$ o porque no querían trabajar $(16,2 \%)$. Quienes tuvieron trabajo tenían una ocupación calificada media el 50,2\%, un $26,1 \%$ con una ocupación calificada alta y un $23,4 \%$ en trabajos no calificados. El $58,1 \%$ eran asalariados y un $35,4 \%$ eran trabajadores por cuenta propia e independiente.

Otra fuente de información sobre la situación reciente de las personas con discapacidad la ofrece el Boletín Discapacidad en Acción de la Defensoría de los habitantes en Costa Rica, en el cual se mencionan 450 denuncias por vulneración de derechos en 2019. Un 68\% corresponden al impedimento de acceso a la seguridad social, debido a que esas personas lo solicitan mediante el régimen no contributivo, situación asociada con las condiciones sociolaborales de ese grupo (Defensoría de los habitantes, 2020).

Con respecto a los estudios sobre discapacidad en el país, se constata un predominio desde el área de Educación. En los trabajos finales de graduación en la Universidad de Costa Rica (2017-2020) también se hace investigación desde áreas como Derecho y Trabajo Social.

Un balance de la etapa en estudio 1980-2020 muestra que la institucionalidad creada en las etapas previas, así como las disposiciones y la firma de convenciones internacionales, fueron esenciales para mantener condiciones relativamente 
buenas para las personas con discapacidad en el país, a pesar de que, en los años recientes, Costa Rica atraviesa por una etapa de ajustes, que limita las posibilidades y la calidad en la prestación de servicios en el ámbito de la salud, la educación, el empleo, la vivienda, pensiones e ingreso para el conjunto de la población del país.

\section{CONCLUSIONES}

Las gestiones, disposiciones y el surgimiento de instituciones para las personas con discapacidad en Costa Rica fueron iniciativas que partieron de actores individuales y sociales desde el nivel local, estatal, civil, religioso e internacional, donde fue común el predominio de unos sobre otros y la coexistencia de estos. Igualmente, se contó con la participación de médicos, terapeutas, enfermeros, educadores y abogados y la misma población objeto de atención, lo que fortaleció las políticas hacia ese sector.

En el transcurso del período en estudio, los avances en salud y educación, así como el diagnóstico precoz, integral y multidisciplinario, y la protección en los accidentes de trabajo, fueron aspectos importantes para la atención de la población con discapacidad.

Dentro de las conquistas para ese sector, se pueden citar un sistema de atención en salud especializado, bajo el amparo de la seguridad social; un sistema de educación dentro de los marcos del sistema nacional; un régimen de pensiones; una legislación y normativa para garantizar los derechos de la población con discapacidad.

Desde el siglo XIX y hasta el presente, los diferentes actores que intervinieron en la atención para la población con discapacidad configuraron cuatro modelos: el modelo tradicional donde las personas recibieron la denominación de lisiados, impedidos y se constituyeron en sujetos de susceptibilidad de asistencia, caridad, protección y cuidado. El segundo modelo fue el de rehabilitación, donde la atención se centró en la intervención profesional de especialistas para restablecer capacidades en el individuo. El siguiente modelo se ha llamado de autonomía personal, con equiparación de oportunidades y facilitador del entorno físico y social. El último modelo toma en cuenta la inclusión y los derechos para ese grupo. Los distintos conceptos y modelos de atención calaron tanto en la comunidad de profesionales ligados a la atención del grupo con discapacidad como en la política pública del país en esa etapa.

Los entes rectores, el CNREE (1973) y CONAPDIS (2015), han tenido la responsabilidad de promover y fiscalizar el cumplimiento de los derechos de la población con discapacidad para favorecer su inclusión social, bajo el amparo de disposiciones internacionales y de la legislación nacional. 


\section{REFERENCIAS BIBLIOGRÁFICAS}

Acevedo, R. et al. (2016). «Estimación de la prevalencia de enfermedades asociadas a ceguera prevenible y discapacidad visual Costa Rica 2015». San José, C.R.: EDNASSS-CCSS, recuperado de https://repositorio.binasss.sa.cr/repositorio/handle/20.500.11764/626. Última consulta: $9 / 08 / 2020$.

Archivo Nacional de Costa Rica. Serie Congreso y Serie Guerra y Marina (1862-1907/1921 y 1948).

Blanco, E. y Sánchez, A. (2006). «Enfoque de la discapacidad en los organismos internacionales». Revista del Ministerio de Trabajo y Asuntos Sociales 65, recuperado de https://sid.usal.es/ idocs/F8/ART9501/Est03.pdf. Última consulta: 9/08/2020.

Bотеу, A. (2013). Los actores sociales y la construcción de las politicas de salud del Estado Liberal en Costa Rica (1850-1940). Tesis (Sistema de Estudios de Posgrado). Universidad de Costa Rica.

Campos, M. (2013). «La población con discapacidad en los censos de población del siglo xx en Costa Rica». Población y Salud en Mesoamérica, 11 (1): 1-43, recuperado de https://www.redalyc. org/articulo.oa?id=44628565001. Última consulta: 9/08/2020.

Campos, M. (2015). «Los primeros pasos hacia la enseñanza especial en Costa Rica». Revista Actualidades Educativas en Educación, 15 (1), recuperado de https://revistas.ucr.ac.cr/index.php/ aie/article/view/17726. Última consulta: 9/08/2020.

Caja Costarricense de Seguro Social (2002). Hospital Nacional Psiquiátrico. Memoria.

Censo de población de Costa Rica, 1864, recuperado de http://www.ccp.ucr.ac.cr/bvp/censos/1864/1864c06-cr.pdf. Última consulta: 04/04/2020.

Censos de población de Costa Rica 1927, 1950, 1963, 1973, 1984, 2000, recuperado de http:// www.ccp.ucr.ac.cr. Última consulta: 04/04/2020.

Código Militar de la República de Costa Rica 1871, recuperado de http://www.asamblea.go.cr/ sd/Otras_publicaciones/C\%C3\%B3digo\%20Militar\%20de\%20Costa\%20Rica\%201871. pdf. Última consulta: 04/04/2020

CONAPDIS e INEC. ENCUESTA NACIONAL SOBRE DISCAPACIDAD 2019, recuperado de https://www. inec.cr/sites/default/files/documetos-biblioteca-virtual/reenadis2018.pdf. Última consulta: $9 / 08 / 2020$.

Decreto Ejecutivo 2, 1926. Reglamento de Inspección Médica de las Escuelas.

Decreto Ejecutivo 26831 del 23 de marzo de 1998. Reglamento de la Ley 7600.

Defensoría de los habitantes. Boletín Discapacidad en Acción, recuperado de http://www.dhr. go.cr/informacion_relevante/revistas/Dis-capacidad.aspx. Última consulta: 9/08/2020.

FARfán, G. (2007). «El nuevo institucionalismo histórico y las políticas sociales». POLIS 3, (1): 87124, recuperado de http://www.scielo.org.mx/pdf/polis/v3n1/v3n1a5.pdf. Última consulta: 04/04/2020.

González, C. y Solís, E. (1989). El ejército en Costa Rica: Poder politico y poder militar 1870-1890. Tesis. Universidad de Costa Rica.

Lachner, V. (1902). «Apuntes de higiene pública, organizaciones, instituciones y profesiones relacionadas con ese ramo". Revista de Costa Rica en el siglo XIX, tomo I. 
Ley 14. Ley de organización del Ejército, 1898 (1978). Tipografía Nacional, Centro de Investigaciones Históricas de América Central. Repositorio Carlos Meléndez. Versión digital, recuperado de http://repositorios.cihac.fcs.ucr.ac.cr/cmelendez/handle/123456789/84. Última consulta:

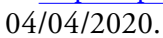

Ley 61. Ley constitutiva de la Escuela de Enseñanza Especial del 15 de marzo de 1944.

Ley 2171 del 30 de octubre de 1957. Ley del Patronato Nacional de Ciegos. Sistema Costarricense de Información Jurídica, recuperado de http://www.pgrweb.go.cr/scij/Busqueda/Normativa/ Normas/nrm_texto_completo.aspx?param1=NRTC\&nValor1=1\&nValor2=38462\&nValor3=40550\&param2=1\&strTipM=TC\&lResultado=3\&strSim=simp. Última consulta: $04 / 04 / 2020$.

Ley 2160 del 25 de Setiembre de 1957. Ley Fundamental de Educación. Sistema Costarricense de Información Jurídica, recuperado de http://www.pgr.go.cr/scij/index_pgr.asp. Última consulta: 04/04/2020.

Ley 5347 del 11 de noviembre de 1973. Ley de creación del CNREE. Sistema Costarricense de Información Jurídica, recuperado de http://www.pgrweb.go.cr/scij/Busqueda/Normativa/Normas/nrm_norma.aspx?param $1=$ NRM\&nValor1=1\&nValor2=10613\&nValor3=100851\&strTipM=FN. Última consulta: 04/04/2020.

LeY 52 del 12 de MARzo De 1923. Ley de protección de la salud pública. Sistema Costarricense de Información Jurídica, recuperado de http://www.pgrweb.go.cr/scij/Busqueda/Normativa/ Normas/nrm_texto_completo.aspx?param1=NRTC\&nValor1=1\&nValor2 $=31262 \& \mathrm{nVa}$ lor3=32975\&param2=1\&strTipM=TC\&lResultado=1\&strSim=simp. Última consulta: $04 / 04 / 2020$.

Ley 7600. Ley de Igualdad de Oportunidades para las personas con discapacidad. La Gaceta 102 del 29 de mayo de 1996.

Malavassi, A. (1998). «Cotidianidad marginal. La lúgubre y frugal vida al interior del lazareto general del Estado de Costa Rica (1833-1850)». Revista de Historia, 38, recuperado de https://www. revistas.una.ac.cr/index.php/historia/article/view/2032. Última consulta: 04/04/2020.

Martínez, J. (2007). Regímenes del bienestar en América Latina. Fundación Carolina, recuperado de https://www.fundacioncarolina.es/wp-content/uploads/2014/08/DT11.pdf. Última consulta: 04/04/2020.

Miangolarra, J. et al., (2003). Rehabilitación Clínica Integral. Funcionamiento y discapacidad. Barcelona: Masson.

Murillo, S. (1992). Evolución histórica conceptual y práctica de la rehabilitación en Costa Rica (19401990). Tesis SEP. Universidad de Costa Rica.

Organización Mundial de la Salud (OMS). Temas de salud, recuperado de https://www.who. int/topics/disabilities/es/. Última consulta: 04/04/2020.

Pérez, A. (2012). Resultados relevantes de discapacidad: Censo 2011. CNREE, recuperado de http:// www.conapdis.go.cr/documentacion/estadisticas/Analisis\%20datos\%20censo\%202011\%20 discapacidad.pdf. Última consulta: 04/04/2020.

Ramírez, O. (1998). Factores determinantes de los arreglos de convivencia de la población adulta mayor. Tesis. Universidad de Costa Rica.

Rodríguez, M. (1991). Reseña Histórica. Hospital Nacional Siquiátrico Manuel Antonio Chapuí y Torres, recuperado de https://www.google.es/url?sa=t\&rct=j\&q=\&esrc=s\&source=web\&c$\mathrm{d}=\& \mathrm{cad}=$ rja\&uact=8\&ved=2ahUKEwjTpY_Dy_XsAhUz8uAKHVq7C7UQFjABegQI- 
BBAC\&url=https\%3A\%2F\%2Fwww.binasss.sa.cr\%2Fbibliotecas\%2Fbhp\%2Ftextos\%2Frhistoricahnp.pdf\&usg=AOvVaw18NNENCWLPOZRuFIhUyunS. Última consulta: $04 / 04 / 2020$.

Sistema Costarricense de Información JurídiCa, recuperado de http://www.pgrweb.go.cr/scij/ Busqueda/Normativa/Normas/nrm_texto_completo.aspx?param1=NRTC\&nValor1=1\&nValor2=36711\&nValor3=38700\&param2=2\&strTipM=TC\&IResultado=13\&strSim=simp. Última consulta: 04/04/2020.

Viales, R. (2008). «Construcción, trayectoria y límites del régimen liberal en Costa Rica». Revista Diálogos, 9 Número especial. DOI 10.15517/DRE.V910.31245, recuperado de https:// revistas.ucr.ac.cr/index.php/dialogos/article/view/31245. Última consulta: 09/08/2020. 
